\title{
The Impact of Teaching English Past Tenses through Literature in Sudanese EFL Classrooms on the Promotion of Students' Performance
}

\author{
Ezzeldin Mahmoud Tajeldin Ali (Corresponding author) \\ Gadarif University, Eastern Sudan \\ E-mail: ezzeldin333@yahoo.com
}

Abu Adam Osman Mahmoud Ahmed

Gadarif University, Eastern Sudan

Received: 22-08- 2014

Published: 01-05- 2015
Accepted: 24-11- 2014

doi:10.7575/aiac.ijalel.v.4n.3p.1
Advance Access Published: December 2014

URL: http://dx.doi.org/10.7575/aiac.ijalel.v.4n.3p.1

\begin{abstract}
This study attempts to examine the effect of using English literary texts in teaching the past simple and past perfect tenses of English as a foreign language (EFL) at the secondary schools' level, in Gadarif province, in Eastern Sudan. Teaching English through literary text was done adjacent to a school syllabus called Sudan Practical Integrated National English (SPINE) for comparison purposes. On the basis of an experimental approach, pre tests and post tests were taken by 85 students; 42 students were chosen for the experimental group and 43 for the control group. The purpose behind the pre-tests was to give information about the learners' knowledge of English grammar before any training took place. After the pre tests, the two groups attended language classes through two different methods (SPINE and Literature). The language classes continued for five weeks after which students in the two groups have taken post tests. Results obtained via the tests, revealed that the teaching of English past tenses through literature proved to be more effective than through SPINE. The experimental group has relatively higher scores in comparison to the control group. The computation of the coefficient correlation showed a significant difference.
\end{abstract}

Keywords: Literary text, effective, effect, multidisciplinary

\section{Introduction}

The art of teaching English as a second or foreign language (ESL/EFL) witnessed great changes throughout its history. Applied linguists and language teachers exerted a big effort establishing language teaching methods. However, every time, a language teaching method came, it did not work long but another one pursued it claiming much for itself while criticizing such a method as inadequate. This kind of criticism often forms a two-sided weapon. It provides some sort of assessment regarding the good sides of the method concerned. But criticism such as this often abruptly causes a language teaching method to go to the store of history even before having a complete turn. The Grammar Translation Method (GTM) was one of the early attempts of ESL/EFL teaching that is no longer used at present. The GTM is based on the translation of literary texts of a second/foreign language into the native language. Thus, translation forms the main learning activity of this method where literary works represent notable sources of materials in ESL/EFL classrooms. One of the adequacies of the GTM is the use of literary texts that represent the most versatile, timeless and interesting material to be used in English language teaching, in any respect. These characteristics are arguably enough to prepare the GTM for prospective use. Furthermore, they can label literature as integral for understanding English grammar efficiently. However, the GTM was replaced by the Structural Approach (1960s-1970s) consequently literature was no longer used as a technique of language teaching. The Structural approach focused on the teaching of English grammar ignoring the content, interpretation of written word or style. Thus, the Structural Approach dealt only with the teaching of English language structures (Brown 2000). Other approaches followed including the Direct Method, Audio-lingualism, Communicative Approach, task-based language learning, Total physical Response, the Silent Way, and the Natural Approach, etc. These approaches successively dominated ESL/EFL setting out different objectives of English teaching (Zainuddin, et al 2011). All through this history no formal effort has been exerted towards the involvement of literature in English language teaching. Linguists and language teachers who are interested in language teaching recently have started developing trends towards the teaching of English language through literature. These new trends probably take place due to research conclusions that point to literature as an effective technique for language teaching (Brumfit and Carter, 1986, and Little and Wood, 2005, Alam 2002). Krashen (1982) states that as the themes of stories are popular and known everywhere in the world, such stories can function as an helpful filter enabling younger learners to learn a language fast. Kellem, (2009) explains that teaching stylistic analysis of a literary text gives students a chance to illuminate the formal features of English grammar, etc. 
This study attempts to examine the efficiency of using literature in the teaching of English as a foreign language. Specifically, it seeks insight into the efficiency of using literary texts in English language teaching in a Sudanese Secondary School Classroom. Arguably, as an English language syllabus, the Sudanese Practical Integrated National English (SPINE) per se is not adequate enough; a literary text-based-syllabus can do a better job in teaching of English grammar. Thus, the study attempts to strengthen the argument for recommending the involvement of doses of literary texts for English grammar teaching. The study will adopt an experimental approach measuring the utility of literary texts as a more effective teaching technique/material of English language in comparison to SPINE.

\section{Literature Review}

The teaching of English as a foreign language (EFL) in Sudan as previous studies reveal, forms a challenge that arises due to several reasons. According to Ali (2011) text books used do not consider many of the essential educational requirements such as the learners' level of English, attitudes, interests, etc. The contents of these syllabuses are not genuine, that are presented at a high level of language demanding much from the learners. Moreover, the contents of these courses do not meet the prospective needs of the learners and are often too large to finish within a term. Al Hassan (2011) states that the English language syllabus (SPINE) has been designed in a traditional way and the cultural items it includes are not representative that cause the syllabus to lack much of its properties as a textbook of foreign language. Presently, the teaching of English grammar through literature has become the concern of linguists and language teachers on local and international scales.

Some other researchers see teaching English grammar through literature as a multidisciplinary instruction trend. Multidisciplinary trend integrates two or more disciplines making advantage of the close interrelation between such disciplines. It also bases on a natural philosophy that views the learning things such as language and literature a whole and as isolated things. Thus, multidisciplinary strategy functions as a suitable instruction that enables EFL learners to fully understand English grammatical rules integrating them with literature discipline (see Al Hassan 2012).

Literary texts help students learn grammatical rules such as tenses. According to Falvey and Kennedy (2000) we can use literary elements such as plots in teaching the structures of English language at secondary school level. For example, the plot element can help students understand the difference between tenses such as past and present tenses where students need to think about how a sequence of past events should be. Referring to the plot they will then learn that events are chronologically sequenced; i.e., in the past simple and the past perfect, etc. The theories of material organization provide a number of criteria in relation to the selection of teaching material regarding teaching a language through literature.

The efficiency of literary texts in developing linguistic competence is probably resulting from the use of the authenticity of such literary texts as Collie and Slater (1987 and 1990 confirm. This is because being so versatile and undying material such literature can be powerfully supportive in the field of language teaching and capable of fostering the development of the four skills. Through such target language literature we can achieve the knowledge of language fluency that we target. Similarly, Smita and Mujumdar (2010) state that literature can be used to remove the linguistic obstacles that non-native learners of English face learning English language. Literary texts represent suitable context that we can use to accelerate the syntactic knowledge of learners (Arthur 1968).

Brumfit and Carter (1986), Little and Wood (2005) and Alam (2002) report that the teaching of a language through literature increases all language skills of learners extending their linguistic knowledge such as syntax. If we consider literature as source of ELT, we may need to discuss the issue that some EFL teachers often have difficulty managing literary texts. It is probably because they do not have literature-based language textbooks or teaching guidelines or because educational authorities give very little care to the idea of the involving literature in language teaching. Consequently, many oversea EFL teachers have great difficulty distinguishing between the use of literature of as a language teaching material and literature as a technique for language teaching. Maley (1989) found that the teachers of English overseas confuse between the study of literature and the use of literature as a technique for teaching language. The use of literature as a source for language learning requires a very different approach. It requires the tailoring of activities that fit the level of students.

\section{Teaching Materials and Instructions}

\section{A. Literary text (Oliver Twist)}

A simplified version of Oliver Twist is used as the literary text of this study is arguably seen as the most suitable text for the students in language levels of syntax, words, style, etc. Through this text students can understand the target English grammar items easily. Students are taught the whole version chapter by chapter. Literary elements such as plots, subplots, etc., are given more attention, that form integral parts for understanding tenses such as simple past and past perfect tenses and the differences between such tenses. Exercises that take the forms of continuous assessments are done by students. In these exercises students assign the types of tenses used on sentence level figuring out how and for what purpose the author used them. As instructions, the teacher asks students to think of how a sequence of past events should be. After discussing the plot carefully they will then learn that events are chronologically sequenced which will enable them learn the differences between the past simple and the past perfect, etc. (see Falvey and Kennedy 2000).

\section{B. Sudanese Practical Integrated National English (SPINE)}

The Sudan Practical Integrated National English (SPINE) refers to series of six textbooks; versions 1, 2 and 3 that are assigned for the basic school level, while 4, 5 and 6 are assigned for the secondary school stage. SPINE series textbooks 
have been designed by the Sudanese Ministry of Education around 1990 with the support of some native speakers (see El Hassan 2011). According to Arora (2003) the textbooks serve as a formal syllabus for the basic and secondary school levels. The specific objectives behind these textbooks are to develop the students' skills of English language on the basis of a communicative approach utilizing a mixture of local and international culture items.

At the secondary schools, SPINE textbooks 4,5 and 6 are taught respectively at three classes within three years. SPINE textbooks are accomplished by teachers' guide books where most of the lesson plans are based on Presentation, Practice and Production (PPP) (see Sptratt 2007). To achieve the objectives previously mentioned, SPINE introduces a number of sections which comprise reading, writing, discussion and grammar corner, however, there no clear sections for listening, speaking or pronunciation skills. Although the content of the textbook is relevant to Sudan cultures; it is inadequate in various aspects. The editing of the whole textbook is horrible which lacks standard colors, patterns, sequencing of items, skills distribution, etc. For example, the reading passages are stuffed with many new words which demand much effort from students to learn. Moreover, grammar items extracted from such passages, 'grammar corner' are presented in an abrupt way. That is, practice activities/exercises allowed for each language aspect are not sufficient enough. Consequently students need to do very few exercises to practice many language skills, in a short period of time. Thus, the limitedness of activities accompanied by other difficulties such as the too long texts full of spelling infelicities, they trigger students' dissatisfaction. The final result of this is the poor performance of English language at the secondary school level in the Sudan. Moreover, students have taken negative impressions about English lessons due to the boring output of the textbooks taught.

It seems that the educational authorities in the Sudan need to consult such textbooks devising an alternative syllabus that works alongside of the formal secondary school syllabus of English language. Assumingly, the teaching of English through literature forms an optimal alternative syllabus which can contribute to the solution of the problem.

\section{The Study design}

\subsection{Participants}

A number of 85 first year male students of Osman Digna Model Secondary School (Gadarif province, Eastern Sudan) were involved in the study. The students were divided into two groups (A and B) which compromise 42 and 43 students respectively. Demographically, participants are male students whose ages ranged between 15 to 18 years old. In academic terms, these students enjoy high learning abilities and they descend from different basic schools in Gadarif province. After showing high learning abilities in these schools scoring high marks in the final exams, educational authorities collected them into a special school called Model School. The purpose behind this school is to give these bright students a special care at secondary school stage.

\subsection{Data collection}

The data of this study has been obtained by means of pre-and-post tests. These are two versions of pre - and -post tests which have been manipulated to measure the performance of two different subject groups composed of 85 male students. Group (A) represents an experimental group while group (B) represents a control group. Preliminarily, the pretest is administered to determine students' understanding of English past simple and past perfect tenses (baseline knowledge). On the other hand, post-tests are given after instructions (lessons) to determine what the students have learned.

\subsection{Data analysis}

We applied an independent study design or between groups/subjects (Filed 2009). This statistical measurement allows us to compute performance difference between groups. Using this measurement we computed the total means of the two groups as well as the coefficient correlation.

\subsection{Training}

Training took place in April/May 2012-2013.There are two groups of students A and B. The groups received training on two different courses. Students in group (A) were taught English grammar through literature. The literary text used here was a simplified story of Oliver Twist. On the other hand, the students in group (B) were taught English grammar through SPINE4. Classes continued for five weeks. During this period both students in groups A and B attended the classes regularly. They were well satisfied with the way teaching was done. In the end of the training, the students took post-tests that were based on the content of the instructions they had learnt.

\subsection{Test battery}

Testing procedure: To run the pre and post tests, we organized two groups. A number of 42 students participated in the experimental Group (A) while a number of 43 students participated in the control group (B) in both the pre-and post tests. In the first stage, the two groups were asked to take the pre-tests without having any sort of training in relation to the syllabuses targeted. The purpose behind the pre-tests is to measure the learners' existing knowledge of English grammar (tenses and parts of speech) through the two different methods. In the second stage, both groups A and B have taken post tests on the same grammar items through the same two methods mentioned previously. In each test candidates were asked to answer 30 test items of English grammar about past simple, past perfect tenses and the parts of speech. 


\subsection{Testing techniques and scores}

Designing the test/s, we adopted objective testing techniques which are assumed to be less confusing than open ended questions. Test items included testing multiple, complete, fill in the blanks and sentence ordering tasks. Regarding the scoring procedures, the test consists of 40 objective test items where each test item is assigned 1 mark if correct and 0 if wrong answer. In this case the scores of each candidate can be added together to arrive at a total of what candidates has scored (whole performance) (Alderson, et al; 2005).

\section{Results}

In this section we will present the results of this study including pre and post tests of the ways of data collection and the discussion of the results. Results of pre- and post tests based SPINE4 syllabus.

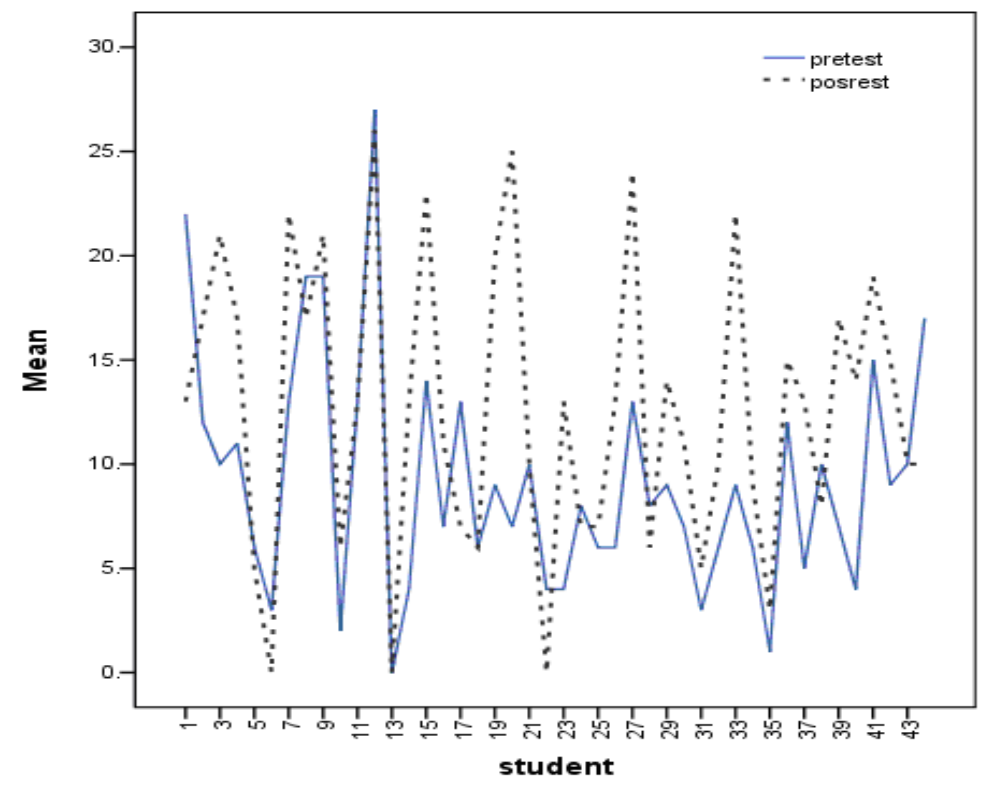

performance of Sudanese students of pre-and post tests based on SPINE4syllabus.

Figure 1. The

As figure (1) shows the scores of the students in the post-test does not differ a lot from their scores in the pre-test which was based on teaching English through Sudanese Practical Integrated National English (SPINE4). Interestingly, the computation of the correlation relation shows strong statistical significant difference where $r=600(p<01)$. We will discuss factors leading to such difference later in the next section.

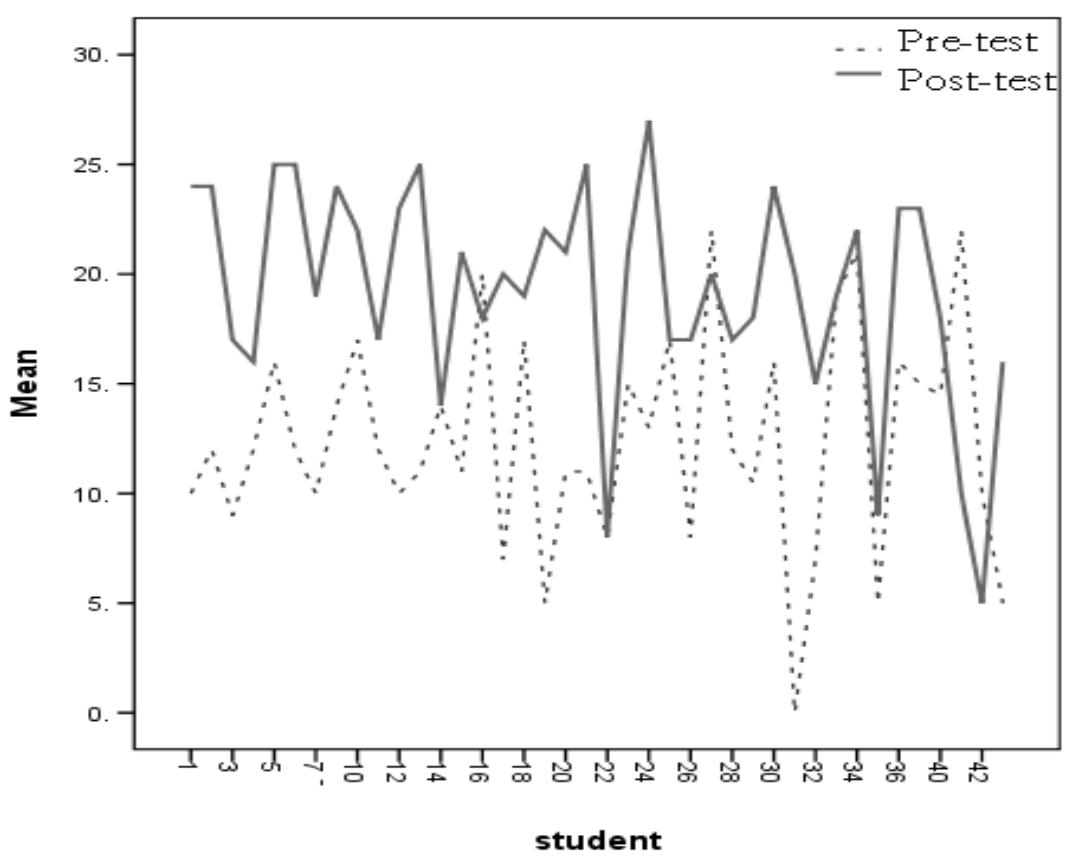

Figure 2. the performance of Sudanese students in pre- and-post tests based on teaching English through literature.

As figure (2) shows students have relatively low scores in the pre-test in comparison to their performance in the posttest. Most of the results of the students in the pre-test range between $15 \%$ and $33 \%$ while in the post-test their scores 
range between $33 \%$ and $65 \%$. The computation of the correlation relation shows statistically significant difference where $r=337(p<.05)$. Reasons for this difference will be discussed later.

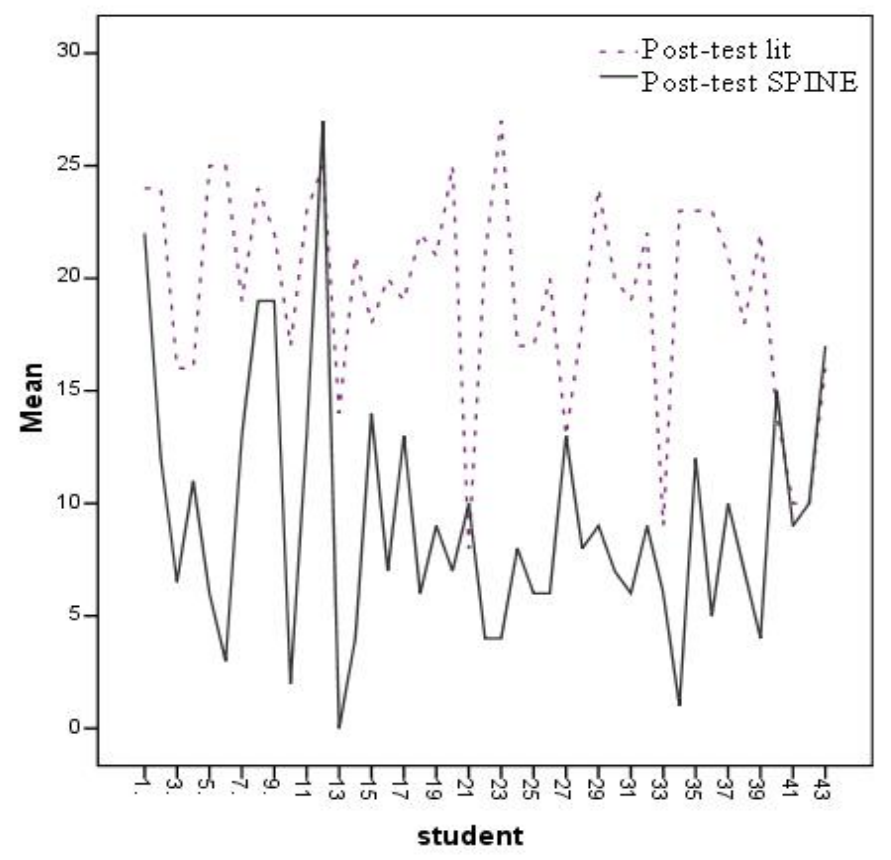

Figure 3. total mean of the performance of experimental and control groups in post-tests. Teaching method of experimental group is literary texts (Oliver Twist Story), while that of the control group SPINE (4) syllabus.

Results in figure (3) shows the data are lined up in perfect parallel lines, which suggest that some correspondence arises between the two data. One possibility to describe these results is that students have reasonably higher scores in the post test when they are trained on literary-based text than when they are trained on SPINE4. Moreover, data shows a statistically significant difference between the two data where the correlation is $(\mathrm{r}=337, \mathrm{p} .05)$. Discussion of this data will take place in the discussion section.

\subsection{Discussion}

The above results suggest that teaching English through literature is better than the teaching of English language through Sudanese Practical Integrated National English syllabus (SPINE4). This appears so because students who received training on English through literature scored higher marks than those who received training on English through SPINE. In this point our results converge with (Brumfit and Carter 1986, Little and Wood 2005, Fakrul Alam 2002). One possible interpretation for this improvement is that students found the teaching of English past tenses through literature more interesting and has stronger motivational power. On the other hand, students trained on SPINE (4) show poor performance in both the pre-tests and post-tests. This is probably due to the fact that students did not benefit a lot from the training based on SPINE (4) syllabus, which implies that the motivation of the students towards SPINE (4) to learn English language was not very great. It also possible to refer degradation of the students' performance to motionless correspondence of these students to lessons delivered through SPINE syllabus.

\section{Conclusions}

Teaching English through literature forms an effective means of past tenses teaching. Success probably occurs due to the interesting context which students find in literary texts.

In comparison to SPINE syllabus, literary texts proved to be more effective method for good understanding of the past simple and past perfect tenses of English.

In this paper students learn English language tenses more effectively through literary texts than through uninviting formal syllabuses.

Complexity and diversity of literary texts represent a challenge that requires students to do more effort learning the grammatical items properly.

\subsection{Recommendations}

On the light of the conclusions above the study recommends the following:

Educational authorities should establish an English language syllabus that introduces language grammar through literary texts at secondary school level. This syllabus should be used adjacent to the formal language course.

Simplified copies of English literature such as Oliver Twist, Great Expectations, Things Fall Apart, Treasure Island, etc., are very much recommended as formal literary. 


\section{References}

Alderson, J.Ch., C. Calpham, \& D. Wall. (2005). Language Test Construction and Evaluation. Cambridge University Press, UK

Al Hassan, I., B. M. (2012). Multidisciplinary Curriculum to Teaching English Language in Sudanese Institutions. (A Case Study). Theory and Practice in Language Studies, 2(2), pp. 402-406

Al-Hassan, I. B. M. (2011). The portrayal of local and the international cultures in the Sudanese English Language Syllabus (SPINE). Global Journals: Human Social Science, 11(7).

Amer, A. (2003). Teaching EFL/ ESL Literature. The Reading Matrix, 3(2), 63-73.

Ali, E.M.T. (2011). Speech Intelligibility Problems of Sudanese EFL learners.(published PHD dissertation)

Arora, G.L. (2003). Sudan Basic Education Sub-Sector: Study Analysis of Curriculum and Suggestions for National Curriculum Framework UNESCO Consultant - ed/Bas/pe/2004/conf/I/H/2.

Arığul, S. (2001). Teaching of Reading Through Short Stories in Advanced Classes. (Unpublished M.A Thesis). Ankara: Hacettepe University.

Arthur, B. (1968). Reading literature and learning a second language. Language Learning, XVIII: 199-210.

Brown, H. D. (2000). Principle of Language Learning and Teaching. Addison Wesley, Longman, INC.

Brumfit, R. \& Carter, R. (1986). Literature and language teaching.(ed). Oxford University Press

Brumfit, C. J., \& Carter, R. A. (1986). Literature and language teaching. Oxford, UK: Oxford University Press.

Carter, R., R. Walker. \& C. Brumfit. (1989). Literature and learner: methodology approaches. Modern English Publications and the British Counsel

Carter, R., \& McRae, J. (Eds.). (1996). Language, literature, and the learner: Creative classroom practice. London, $\mathrm{UK}$ : Longman.

Collie, J \& S. Slater. (1987). Literature in the language Classroom. Cambridge University Press, Cambridge, UK

Collie, J. \& S. Slater. (1990). Literature in language classroom: A Resource Book of Ideas and Activities. Cambridge: Cambridge University Press.

Elklic, G., ErGgen, G. E., Kayintu, A \& Karaca, H. (2011). The Use of Literature in Teaching English Grammatical Structures as well as Some Linguistic Components: 1st International Conference on Foreign Language Teaching and Applied Linguistics May 5-7 2011 Sarajevo.

Falvey, P. \& P. Kennedy. (2006). Learning Language through Literature: A source book for Teachers of English in Hongkong Oxford University Press .

Kellem, H. (2009). The Formeaning of Response Approach: Poetry in the EFL Classroom”. English Teaching Forum, 47(4), 12-17.

Krashen, S. (1982). Principles and Practice in Second Language Acquisition. New York: Prentice -Hall.

Maley, A. (1989). Down from the pedestal: literature as a resource. In Brumfit, C.J. \& Carter, R.A. (Eds.), Literature and the learner: Methodological approaches (pp. 10-23).London: McMillan.

Little, Wood, W. T (1986). Literature in the School Foreign Language Course.» Literature and language Teaching Ed. C. J. Brumfit and R. A. Cárter.

Sptratt, M., A. Pulverness \& M. William. (2007). The TKT Course. Cambridge University Press

Smita A. \& M.A.Mujumdar. (2010). Teaching English Language and Literature in Non-Native Context, Language in India www.languageinindia.com V (10)

Ileen, A., Morsales, C. , Jones, C. Carmen, Yahya, N. \& Zainunddin H. ( 2011). Fundamentals of Teaching English to Speakers of Other Languages in K-12 Mainstream Classrooms," 3rd ed. (C) 2011 Kendall Hunt Publishing Co.www.kendallhunt.com/ariza.

Rai, A. (2012). Use of Literature in Teaching English. International Journal of Educational Research and Technology IJERT: Volume 3 [3] September 2012: 71 -80. 


\section{Appendix}

\section{A written paper-pencil- test}

This appendix represents the test of English grammar (past simple and past perfect tenses) used in the pre-and-post tests: November 2012

First Year Students, Private Secondary School for boys

Subject: English Grammar Time: Hour

Index no:

Class:

Question One: Put the verbs between brackets in their correct form:

(20 marks)

1. The ministry of Education ( open) a number of new schools in Gadarif last year.

2. I. (be) born in 1977.

3. When Sudan (get) its independence?

4. Ali. (not go) to school last week because he (be) ill.

5. Mona (visit) her aunt in Halfa a month ago.

6. (watch) the foot ball match yesterday?

7. We . (spend) our last holidays in Kassala .

8. They had pay tuition fees last week, you ? (do).

9. Farmers ............... (must) spray their crops last year, unluckily, the pesticide in the area. (not clean ) some of the classrooms yesterday.

10. The cleaners (build) in the year 1995.

11. Many secondary schools in Gadarif

12. They..... (not invite) us for Tahir's farewell party on last Friday did not they?

13.Mr. John ( have) a nice car in 2011.

14. you. ( bring) your exercise book yesterday?

15. In the past people traveled on camels and donkeys they? (do).

16. I ( not, know) that man yesterday, but my friend told me who (be).

17. Mona. (iron) the clothes two hours ago.

18. Why he (come) late last Friday?

19. Farmers were so happy last year. they? (be).

20. Students could not pass the exam, because they

Question Two: Write the verbs given in bracket in the past perfect tense.

10 marks

1-The teacher asked us to describe the match that we. (watch)

2-He left the office earlier since the secretary. ..(tell) about him the meeting.

3-The government spent much money in the school it .(build)

4-We lost to the car which we (buy) last year. 
5-The mail order house did not send me the shirt that I. (order)

6-I used fertilizers since the land. (become) poorer.

7-Marry () the exam, for she. (practise) hard.

8-The bus ..just (leave) when Jack arrived at the station

9- The criminal just .(escape) away when the police arrived.

10- Guests ..(arrive) a few minutes before the party started.

Question Three: Read the text below and then underline the verbs put into the past simple and past perfect 10 marks

I do not believe I (get) that apartment. I (submit) my application last week, but I did not think I had a chance of actually getting it. When I (show) up to take a look around, there were at least twenty other people who (arrive) before me. Most of them (fill, already) out their applications and were already leaving. The landlord said I could still apply, so I did.

I (try) to fill out the form, but I couldn't answer half of the questions. They (want) me to include references, but I didn't want to list my previous landlord because I (have) some problems with him in the past and I knew he wouldn't recommend me. I (end) up listing my father as a reference. It was total luck that he (decide) to give me the apartment.

\section{The end of test}

